\title{
El portavoz del aperturismo moderado: el protagonismo discreto del Ya durante la Transición Española ${ }^{1}$
}

\section{The press platform for moderate change: the discreet role of the Madrid daily Ya during the Spanish Transition}

\author{
Christopher D. Tulloch. Universitat Pompeu Fabra (christopher.tulloch@upf.edu)
}

Recibido: 28/11/2017 - Aceptado: 15/03/2017

\section{Resumen:}

En este artículo se analiza uno de los aspectos menos estudiados sobre la relación entre la prensa española y la Transición: el papel del diario católico Ya, líder de ventas entre los rotativos madrileños a la hora de producirse el cambio democrático. En el panorama periodístico de la época, Ya ocupa un lugar singular: está desligado de la prensa del Movimiento, no pertenece a la tradición monárquica de $A B C$ ni La Vanguardia y se encuentra a una distancia ideológica notable de la nueva prensa postfranquista representada por El País. A través de un análisis de contenido de más de 600 editoriales de la época, este artículo demuestra cómo este diario conservador navegó entre las aguas turbulentas del momento y cómo se enfrentó al desafío de apostar por la vía reformista, el aperturismo político y las nuevas reglas del juego democrático sin perder el sentido de moderación y la apuesta centrista que le caracterizaba.

\section{Palabras claves:}

Ya; Transición; prensa; política; cambio democrático

\section{Abstract:}

This article analyzes one of the lesser studied aspects of the relationship between the Spanish press and the Transition: the role of the Catholic newspaper Ya, leader at the Madrid newsstands at the time of Franco's death and democratic change. Ya occupies a singular position in the journalism landscape of the time: it is distanced from the officialist "prensa del Movimiento", it does not belong to the monarchic tradition of ABC or La Vanguardia and it fins itself at a considerable ideological distance from the new post-Francoist press epitomised by El País. Through a content analysis of over 600 editorials at the time, this article shows how this conservative newspaper steered through difficult times and how it faced up to the challenge of supporting the road to reform, political liberalization and the new rules of the democratic game without losing its characteristic sense of moderation and political centrism.

\section{Key words:}

Ya; Transition; press; politics; democratic change

1 Este artículo forma parte del proyecto titulado "PreTrans. El papel de la prensa diaria en la Transición democrática: cobertura informativa y comportamiento político de periódicos y periodistas”, financiado por el Ministerio de Economía y Competitividad (CSO2012-36774). El proyecto se desarrolló entre los años 2013 -2015 bajo el liderazgo de su investigador principal, Dr. Jaume Guillamet de la UPF. 


\section{Introducción}

El papel de la prensa durante la Transición es un campo de investigación científica de un creciente interés innegable entre los estudiosos del periodismo y el poder en la España contemporánea. En relación con ello, existe una bibliografía que se divide en tres grandes subcategorías: i) monografías que nos ofrecen una visión de conjunto (Barrera 1995a, 1995b; Quirosa-Cheyrouze y Muñoz 2007, Castro 2010); ii) textos enfocados sobre temas más específicos de la relación entre los medios de comunicación y la transición democrática, como el papel de los corresponsales extranjeros (Rodríguez-Martínez, 2015; Tulloch, 2015; Guillamet et al., 2016;) o de la prensa nacionalista durante estos años (Caminada, 2016) y iii) trabajos que analizan hasta cinco modelos de medios de prensa española a finales de los años 70.

Estas tipologías incluyen la Prensa del Movimiento como Arriba (Montabes Pereira, 1989; Zabildea, 1996); los diarios ultraderechistas como El Alcázar (Rodríguez Jiménez, 2012); las rotativas prefranquistas marcadamente monárquicas como La Vanguardia o $A B C$ (Zugasti, 2007a, Nogue y Barrera, 2006, Olmos, 2003); los diarios postfranquistas epitomados por $E l$ País y Diario 16 (Seoane y Sueiro, 2004) y, por último, los periódicos madrileños fundados con anterioridad al régimen con publicaciones como Informaciones (Crespo de Lara, 2008) o Ya (García Escudero, 1984).

Mientras el campo de la literatura transicionista está repleto de referencias al comportamiento político de los cuatro primeros grupos, el papel de la prensa madrileña conservadora y prefranquista ha atraído menos la atención de los estudiosos del periodismo de la Transición. El presente artículo ha optado por analizar el protagonismo político y periodístico del diario Ya para ayudar a cubrir este vacío existente, dado que la poca bibliografía de la cual disponemos se compone en mayor parte de monografías de carácter biográfico escritas por antiguos redactores del diario (García Escudero, 1984; Cantavella, 2010).

Ya nació el 14 de enero de 1935, y desde 1939 hasta 1952 fue dirigido por Juan José Pradera, una figura impuesta directamente por el Régimen. Sin embargo, es bajo la dirección de un periodista de la redacción, Aquilino Morcillo Herrera, cuando el diario de la Editorial Católica (Edica) logró su mayor ascensión. En 1974, Morcillo Herrera pasó a ser consejero delegado del diario y fue relevado por Alejandro Fernández Pombo quien fue, por lo tanto, el director durante la mayor parte de la Transición. La democracia trajo resultados económicos negativos para el diario. De ser líder en Madrid en 1975, la difusión del diario bajó a poco más de 100.000 ejemplares en 1980; en 1981 Edica registró sus primeras pérdidas. En 1980 Manuel Jiménez Quílez tomó el mando del diario e inició un proceso de “derechización” del rotativo. Según Alférez, el Ya no acertó "a la hora de vislumbrar el sendero a seguir (y no supo) articular ni las palabras ni el estilo con que dialogar con sus viejos/nuevos lectores". (Alférez, 1986: 19). Durante los años 80, las ventas cayeron de forma continua y en 1996 Ya desapareció.

La elección del diario católico para el presente artículo obedece a cuatro razones. En primer lugar y como se mencionó antes, Yallegó a ser el periódico más vendido en Madrid a mediados de los años 70, con una difusión de 190.000 ejemplares 
a finales de 1975 (Martín Aguado, 2012: 15) elevándose a 200.000 ejemplares los domingos, un hecho que hace que la poca atención que se le ha dedicado resulte aún más sorprendente (Cantavella, 2010: 215). En segundo lugar, a diferencia de Informaciones -que dejó de editarse en 1980 y que tuvo una reaparición muy debilitada en 1981- Ya se publicó durante los años de la Transición de forma ininterrumpida. En tercer lugar, bajo la dirección de Alejandro Fernández Pombo el diario del Edica fue considerado la referencia democristiana y valedor periodístico del nuevo centro político representado por la figura de Adolfo Suárez, ya que no es hasta el año 1980 -y la llegada de Manuel Jiménez Quílez- cuando el diario gira de manera más clara hacia la derecha. Por último, el presente artículo trata de analizar la trayectoria de un diario autodenominado como moderado en tiempos políticos altamente convulsos como los de la Transición, para ver hasta qué punto -y a pesar de ocupar un espacio periodístico distinto al histrionismo de la prensa falangista, la tradición monárquica de sus competidores de prensa conservadora o el fervor prodemocrático de la nueva prensa postfranquista- contribuyó de manera efectiva a un clima aperturista en el entorno político de estos años en España.

\section{Objetivos y metodología}

El presente artículo tiene como objetivo general demostrar la clara voluntad aperturista de un diario que, en un espacio muy reducido de tiempo -doce meses como máximo-, se somete a la metamorfosis de haber sido una publicación en cómoda convivencia con el Régimen a ser un diario que a través de su desarrollismo editorial y su postura política en los momentos definitorios de la Transición contribuyó -de una manera siempre más discreta en comparación con sus competidores- a crear un clima proclive a la democratización de la vida pública española. Por lo que ser refiere a objetivos más específicos, el presente estudio tiene como meta analizar el comportamiento político del diario en relación con los principales protagonistas y con determinados momentos claves de los años de la Transición, para poder ilustrar la política aperturista, los reajustes discursivos y la contribución al debate político de la época del diario.

Para poder llevar a cabo el análisis de la posición editorial del Ya durante la Transición el estudio optó por repartir los años de la Transición en tres bloques y, dentro de ellos, por estudiar determinados temas clave para el transcurso de la misma como son:

i) el cambio democrático (hasta junio 1977): en el caso del año y medio que va desde la muerte de Franco hasta la celebración de las primeras elecciones democráticas se optó por recopilar todos los editoriales de estos 572 días. La intensidad de estos meses queda reflejada en el hecho de que, pese a limitar la muestra a temáticas estrictamente de carácter transicional, se conformó un cuerpo de 502 unidades de análisis, una proporción (88\%) de editoriales políticos realmente elevada. Para el presente artículo y para un manejo más ágil de los datos se decidió limitar el análisis a la muerte de Franco, la figura del Rey, la caída del gobierno de Arias Navarro, el nombramiento de Adolfo Suárez, el referéndum sobre la reforma política, la legalización del PCE y la celebración de las primeras elecciones democráticas. 
ii) el cambio de régimen (hasta diciembre de 1978): en este caso la muestra fue reducida a una cuarentena de editoriales sobre el estado de las autonomías, la amnistía, la violencia terrorista y el camino hacia la Constitución.

iii) el rodaje constitucional (hasta octubre de 1982): el estudio postconstitucional consideró una cincuentena de editoriales que tratan de las elecciones legislativas y municipales de 1979, las autonómicas vascas y catalanas de 1980, la dimisión de Suárez, el golpe de Estado, las elecciones legislativas de 1982 y la llegada al gobierno del PSOE.

Una vez determinado el marco temporal, el estudio procedió a realizar -a través del diseño de una ficha técnica específica² un análisis de contenido de carácter cualitativo exclusivamente del espacio de opinión reservado para la información política del diario, con el fin no solo de describir objetivamente y sistemáticamente el contenido inherente de los textos (Berelson, 1952) sino también para poder "extraer las inferencias válidas y replicables de los textos y el contexto de su uso" (Krippendorf, 2004: 18). Los editoriales -de una media de entre 35-40 líneas y de aproximadamente 500-600 palabras- suelen ser monotemáticos, editoriales dobles e incluso en ocasiones de temática triple. En los casos de los editoriales de temática múltiple, el editorial "corre" hasta la siguiente página. Con una ubicación fija -normalmente la página siete- el diario separa su propia voz de la del resto de firmas que ocupan la sección. Estas firmas varían entre colaboradores habituales, columnistas individuales destacados y-hasta febrero de 1977-el grupo de periodistas, intelectuales, pensadores y políticos responsable de 150 artículos publicados semanalmente entre junio de 1973 y febrero de 1977 bajo el seudónimo de Tácito.

Para muchos observadores, el grupo Tácito fue el abanderado del aperturismo predemocrático. Según Charles Powell, el grupo Tácito era "el núcleo aperturista más cohesionado" y para Vázquez "un referente periodístico durante los años de la Transición [cuyos] artículos determinaron una buena parte del proceso de transición que se vivió en España” (Cantavella, 2010b: 156). Su línea editorial en el tardofranquismo es de un marcado tono democristiano, que se ve plasmado en los contenidos de los artículos publicados en el Ya por esta plataforma que agrupaba políticos como Marcelino Oreja, Leopoldo Calvo Sotelo, Landelino Lavilla y Alfonso Osorio -todos ellos luego ministros del primer gobierno de Suárez y con UCD-, Miguel Herrero de Miñón, José María Gil Robles, Manuel Fraga Iribarne o Fernando Álvarez de Miranda-que luego sería presidente del Congreso-, además de contar con las firmas de pensadores, periodistas o intelectuales como Javier Tusell, Augusto Assia, José Jiménez Blanco o José María Javierre. Sus artículos fueron publicados inicialmente solo en el diario Ya pero luego fueron reproducidos en una serie de rotativos -como, por ejemplo, El Heraldo de Aragón- hasta alcanzar una veintena de cabeceras ${ }^{3}$.

2 Además de aspectos técnicos, la ficha de codificación cubría aspectos más relevantes para este estudio como el equipo de redacción (director, estructura); la naturaleza del rotativo (tendencia política y/o social) y aspectos históricos (significación, temas a los que dedica atención preferente, localización de fuentes). De estos factores, se obtuvieron las variables de estudio necesarias para analizar cada texto. La compilación de la muestra fue posible gracias a las facilidades de consulta y disposición de la hemeroteca de la Universidad Autónoma de Barcelona, cuyos fondos bibliográficos disponen de la colección completa de ejemplares del diario Ya durante esta época en formato papel.

3 La motivación de los autores se ve claramente en el prólogo de un libro -sin autoría clara- titulado Tácito, en donde se explica que “Tácito nace así como una agrupación de hombres que intentan potenciar mucho más lo que les une de lo que les separa, que creen que 
Lo cierto es que la difusión de doctrina política a través de la plataforma de Tácito otorgaba un plus prodemocrático y de oposición moderada al Ya. Según Bardavio, “Tácito es un ejemplo de la oposición moderada al franquismo. Sus propuestas no eran rupturistas pero resultaban sospechosas para el franquismo” (Bardavio: 622). En este sentido Vázquez considera que "Tácito estuvo en el punto de mira de las autoridades gubernativas del momento como un tipo de oposición moderada que defendía la democracia y propiciaba un cambio en la forma de gobierno” (Cantavella 2010a: 156).

Una prueba de cómo Tácito estaba en el punto de mira lo encontramos en la censura del artículo "Los sucesores de Franco", del día 31 de octubre de 1975. Los ejemplares fueron retirados de la calle en su práctica totalidad y a su director, Alejandro Fernández Pombo, le abrió un expediente el Ministerio de Información y Turismo por no dar los nombres de sus componentes. Según el propio Fernández Pombo, "me quedé con el dudoso honor de haber sido seguramente el último director de diarios procesado en el régimen de Franco” (Cantavella 2010a: 269). El día siguiente, y en un editorial, el diario expresó su rechazo a la medida. Según Juan Cantavella, exredactor del diario, "su actitud posibilitaba acercamientos de quienes pensaban que el franquismo no podía mantenerse a perpetuidad, sino que era necesario que tomara las medidas indispensables para abrirse a las nuevas realidades asentadas en Occidente y que muchos de los ciudadanos españoles estaban exigiendo imperiosamente" (Cantavella 2010: 231).

\section{La Transición en las páginas del $\mathrm{Ya}$}

La respuesta editorial a la muerte de Franco combina dos líneas discursivas. En primer lugar, el diario ofrece una lectura positiva de su testamento político. En el editorial del mismo 20-N se habla de él como "la gran figura española del siglo XX" y del "hueco" que deja en la vida española y en la historia "tan grande que cualquier superlativo no hará más que empequeñecerlo". Tácito también se apunta a destacar la trascendencia del personaje al considerar que "con él muere un insigne soldado y uno de los estadistas más importantes de las últimas centurias de nuestra vida política”" En segundo lugar, la figura del Franco está representada en Ya como un facilitador de la Transición, enlace clave para el futuro democrático de España y responsable de la popularidad de la nueva Monarquía. Esto se ve en el editorial del 25 de noviembre titulado "Las colas, factor de primera magnitud", cuando el rotativo expresa su opinión de que

“El postrer servicio de Franco al futuro ha sido la apelación al pueblo español que hace en su testamento político para que se agrupe entorno al Rey como lo hizo con él. Podríamos añadir que, después de muerto, Franco

en este momento histórico es preciso reflexionar y actuar de cara al futuro próximo más que con los ojos puestos en el pasado, que existe un gran sector social, nuevo, cuya estructura es profundamente distinta a la de antes de los años cuarenta y que éste debe ser convocado políticamente para que se oiga su voz y se haga sentir su peso...”, Tácito. Madrid: Ibérico Europea de Ediciones, 1975, p. 20, citado en Cantavella et al. (2010a: 228).

4 Ya. “Testamento político". 21/11/1975. 
ha ganado la última batalla que ha sido ofrecer al Rey, las masas...Significa que la Monarquía no tendrá que edificarse en el vacío...sino sobre la base de una adhesión popular...”.

El diario intenta mirar al futuro y la transferencia de adhesión de Franco hacia el Rey domina la agenda editorial de los días posteriores a su muerte. En el editorial del 28 de noviembre y después de uno de los primeros actos públicos del Rey, el dia-

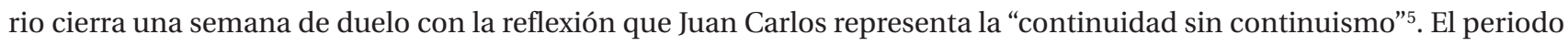
oficial de luto cumplido, Franco desaparece del espacio editorial de Ya hasta el 20 de noviembre del 1976, cuando vuelve a emplear la idea de su figura como responsable del cambio democrático, al constatar "el acierto en sus previsiones para su sucesión en la Jefatura del Estado "para asegurar la Transición en la cúspide sin quebranto”.

\subsection{El Rey: legitimidad, reconciliación, avance}

La afirmación de Zugasti de que "no se puede obviar la existencia de un consenso periodístico... para tratar la imagen de Juan Carlos I... [y que] la prensa fue cómplice suyo sobre todo en la principal tarea de pilotar la democratización del sistema político" (Zugasti, 2007: 338) es evidente en el tratamiento otorgado al joven monarca en las páginas del Ya. Durante los primeros días de su reinado, el diario deja claro tres cuestiones. En primer lugar, que no hay alternativa posible. Para el periódico "él es la única legitimidad y ese principio vale tanto respecto de la institución como de quien la encarna" (García Escudero, 1984: 12). Esta actitud se ve en el editorial titulado "Monarquía nacional" cuando declara que "hace falta estar ciego para no ver que la única Monarquía posible en España es la de don Juan Carlos y que se trata de un tema que hay que dar por definitivamente resuelto"?.

En segundo lugar, Operación Juan Carlos no debe ser vista como el continuismo franquista maquillado como cambio democrático, un posicionamiento que queda claro en el editorial "Rey de los Españoles", del 22 de noviembre, día de su nombramiento:

"La Monarquía no podrá ser un franquismo sin Franco ni debería serlo aunque pudiera. Sólo intentarlo sería la condenación de la Monarquía y de la conciliación que debe conseguir (...) Precisamente hoy nos parece oportuno recoger las palabras que un monarca aragonés dirigió a sus súbditos para recordarles que ellos eran también el Reino: Monarquía somos todos. Yo sólo soy el Rey".

En un artículo sobre el rol del editorial católico en el marco del consenso periodístico de la época, Arroyo Cabello apunta que "durante la Transición [Edica] llevó a cabo una campaña política a favor del cambio democrático por la vía reformista, en clara oposición al continuismo y a la ruptura (...) su objeto era convencer de que el cambio político solo sería posible

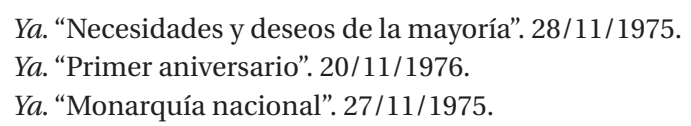


desde la reforma de las instituciones vigentes..." (Arroyo Cabello, 2010: 218). Esta apuesta se ve claramente reflejada en un editorial sobre el mensaje navideño del Monarca, cuando el diario declara que "no puede ni debe ser otro Franco y que es un error, grave y peligroso, el de quienes esperan de él lo que no le corresponde hacer...la Corona está para hacer verdadera la promesa de que después de Franco vendrían las instituciones y para que, tras el protagonismo de una persona, venga el protagonismo de los españoles...”.

En tercer lugar, Ya considera que se debe amortizar la llegada de Juan Carlos para llevar a cabo la denominada "concordia nacional entre las dos Españas". Para el diario, asumir esta función integradora ha de ser "la principal misión de la Corona", que solo se puede llevar a buen puerto si se impulsa y se mantiene un "gran pacto nacional entre todos"9. Según el diario, la insistencia de la Monarquía en este punto "casi raya en obsesión...porque a todos nos incumbe por igual el deber de servir a España y sobre todo, la ilusión de afirmar 'Juntos podremos hacerlo todo’”. Según el rotativo, mientras el Rey puede liderar las iniciativas para lograr la paz social, la responsabilidad última se reparte entre todos: "ahora hace falta que los españoles estemos a la medida de la generosidad con que el joven Monarca, al iniciar su etapa histórica, se ha presentado como el primer servidor de la nación" ${ }^{10}$. En este sentido, el diario muestra su apoyo a las primeras decisiones del Rey como la de no presidir todos los Consejos de Ministros ya que, según él, "debe ser un árbitro y un moderador, un elemento de prudencia y de equilibrio; no puede ser de un partido si ha de ser el Rey de todos" ${ }^{11}$.

Una vez proyectado como referente y símbolo de la conciliación, la esperanza y la ilusión que debe guiar al país en los próximos años, el futuro papel del Rey deja de ser un tema tan dominante en cuanto a los editoriales no firmados se refiere. Aunque la Corona comienza a desaparecer de la primera línea, tiene tres momentos de protagonismo editorial a lo largo de 1976. El primero se refiere al exitoso viaje a los Estados Unidos los días 4 y 5 de junio de $1976^{12}$. El segundo coincide con el anuncio del primer gobierno de Suárez que el diario nomina el "Primer gobierno del Rey", dada la "afinidad entre el pensamiento político del nuevo Presidente y el propósito del Soberano de llevar a cabo una auténtica reforma en profundidad que nos asegure una democracia fuerte y estable"13. El tercer pico de interés viene a finales de noviembre coincidiendo con el primer aniversario de su nombramiento como Jefe de Estado, con artículos como "La Monarquía que esperábamos" 14 o editoriales como "Garantía, la corona”" ${ }^{15}$ en donde el editorial del Ya destaca no solo el "prestigio" y "popularidad entre los españoles” del Rey sino también que "su capacidad como árbitro entre las distintas fuerzas políticas

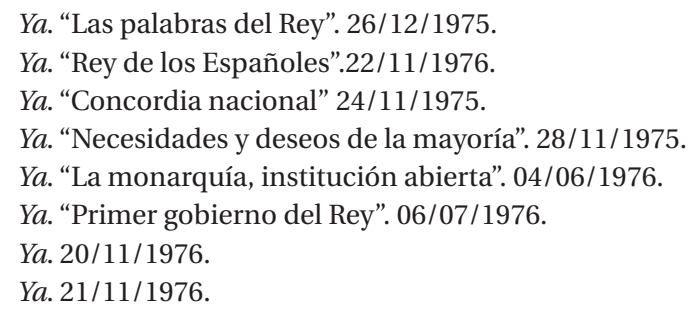


no ha hecho más que aumentar durante el primer año de su reinado y hoy hacen de la Corona la más firme garantía que el pueblo tiene...”. En este año y medio crucial antes de la celebración de las primeras elecciones democráticas está claro que el diario apoya el joven monarca como motor de aperturismo hacia el exterior y como símbolo de concordia, convivencia y moderación.

\subsection{Arias Navarro, obstáculo al cambio}

En vísperas de la elección del primer presidente del gobierno, Ya reclamó “un agente del cambio (...) un hombre que acometa esa labor como principio de la renovación de un sistema anquilosado al que hace falta poner en pie y hacerle andar (...) un gobernante de talante sinceramente democrático con capacidad de convocatoria, que sea conocido y estimado..." ${ }^{16}$. Mientras el biógrafo del diario considera que "un hombre de buena fe es el retrato que Ya hizo de Arias..." (García Escudero, 1984: 22-23), el rotativo madrileño deja claro que el elegido no cumple con estos requisitos y no tarda mucho en criticar su gestión. Tácito abre fuego cuando escribe sobre su nombramiento:

“abre un paréntesis de duda entre quienes habíamos propugnado el cambio desde la legalidad. (...) la gestión de la nueva época histórica que se abría con la monarquía de don Juan Carlos requería un programa político nuevo propuesto y dirigido por hombres con nuevas ideas que pudieran sintonizar con las aspiraciones de libertad y democracia de la gran mayoría del país"17.

La ausencia de dotes comunicativas demostrada por Arias en su primer discurso televisivo en directo a finales de enero desespera al diario. En un artículo publicado en las páginas editoriales, José Jiménez Blanco acusa al presidente del Gobierno de un "lenguaje de dialéctica camuflada", de "hurtar el bulto para no comprometerse" y de un "grave error de perspectiva porque se dirigía claramente a las Cortes pero el auditorio era toda la sociedad española...que encontró en su discurso...el mas olímpico desprecio a las auténticas esperanzas del país en este momento” ${ }^{18}$. El diario señala la gran dificultad del presidente del gobierno de salir del círculo vicioso del bunker franquista, por lo que es necesario un programa democratizador claro.

Con la llegada de la primavera, Ya demuestra una prisa patente en sus editoriales ${ }^{19}$. Según el biógrafo del diario, en estos momentos

"no es el Gobierno el que produce los acontecimientos, sino que son éstos los que se precipitan sobre el Gobierno; de ahí que los editoriales de Ya tengan un denominador común: la exigencia de rapidez. Su finalidad

16 Ya. "Presidencia del Gobierno". 02/12/1975

17 Ya. "El primer gobierno de la monarquía" 19/12/1975.

18 Ya. "En directo, Arias". 31/01/1976.

19 Ya. "Urge el calendario" (01/03/1976) "Hay que pisar el acelerador (05/03/1976) y "Importa la urgencia” (29/03/1976). 
constante es instar, urgir, apremiar, exigir al Gobierno que abrevie trámites y acelere su ritmo para corregir la distonía con el cambio vertiginoso de la sociedad" (García Escudero, 1984: 25).

A finales de abril, el diario retira el poco apoyo que le había prestado a Arias Navarro. En el editorial "A la expectativa: Arias" lamenta que "la acogida esperanza se fue helando poco a poco al comprobarse que el programa acometido se traducía en las versiones más menguadas y raquíticas de cada una de las reformas prometidas” ${ }^{20}$. Con su mirada fijada en Adolfo Suárez, Ya se despide de Arias con un agradecimiento por haber "mantenido el orden público" y "haber puesto en la calle los partidos políticos", pero con dos reproches principales: por el "tiempo perdido por las resistencias del bunker" ${ }^{21}$ y por su "falta de conexión entre el Rey como motor decidido del cambio y el anterior Gobierno que, por falta de credibilidad reformista y democrática, hizo necesaria la sustitución del cúspide del ejecutivo”22. A partir de este momento Arias desaparece de las páginas del diario.

\subsection{Suárez: del escepticismo inicial al apoyo incondicional}

Al igual que a sus competidores, el nombramiento de Adolfo Suárez a principios de julio de 1976 coge a Ya desprevenido. Según un observador "se contaba con el cese de Arias, no con el nombre de Suárez; pero ya es sabido que los "papables" no suelen salir papas de los cónclaves” (García Escudero, 1984: 27). El rotativo madrileño expresa abiertamente sus dudas iniciales sobre la capacidad del joven premier. Considera su paso por las filas del Movimiento como un mal augurio para el verdadero cambio democrático al declarar que "la imagen que de él dan su procedencia política y la misma cartera que ha desempeñado no es la más propicia”. Según un redactor del diario en esta época, "El “iqué error, qué inmenso error!” lo escribió Ricardo de la Cierva (...) pero lo pensamos todos” (García Escudero: 27). Dos días después de su nombramiento, el diario publica un texto aún más crítico ya que expone que

"ha causado sorpresa dentro y fuera de España. Dentro porque se barajaban otros nombres más relacionados con el cambio democrático (...) y fuera por el 'estupor general' causado por un nombramiento tan inesperado. Sus servicios al país han sido importantes pero no tantos que permitan poner una respuesta segura en vez de la incógnita actual, por grandes que sean las esperanzas que se pongan en él”23.

Hasta Tácito se sube al carro del escepticismo inicial. En su primer artículo publicado con Suárez de presidente se pueden ver no solo sus dudas hacia el flamante presidente del Gobierno sino también un guiño a quienes eran sus candidatos preferidos previos a la elección final:

\footnotetext{
Ya. "A la expectativa: Arias". 27/04/1976.

Ya. "Lo que esperamos del nuevo gobierno". 02/07/1976.

Ya. "Primer gobierno del Rey" 06/07/1976.

Ya. "Compromiso con el cambio". 06/07/1976.
} 
"no queremos dejar de destacar la perplejidad, la confusión y la preocupación que este cambio en su forma y en su contenido despertó desde el primer momento (...) los esfuerzos de (...) hombres tan notables como Areilza, Fraga, Garrigues, Martín-Gamero o Robles Piquer no deben ser olvidados. Son personas que han demostrado su capacidad y valía, su dedicación al Estado y al país y su indiscutible deseo de contribuir a instaurar la democracia a España"24.

Con estas reservas sobre la mesa, Suárez domina la agenda editorial con editoriales casi a diario y poco a poco va logrando el beneplácito del diario ${ }^{25}$. Las dos bazas más importantes para este apoyo eran la implicación directa del Rey en su nombramiento y la composición de su primer gabinete. En cuanto a la primera, el rotativo destaca con frecuencia la "mayor afinidad entre el pensamiento político del nuevo presidente y el propósito del monarca de llevar a cabo una auténtica reforma en profundidad que nos asegure una democracia fuerte y estable"26. El diario se pregunta si ha habido un "impulso soberano" en la designación de Suárez y si es así "todos nos alegraríamos por cuanto significa que el Rey está dispuesto a jugar su papel arbitral y a no soportar mediatizaciones de nadie (...)”. Por lo que se refiere al segundo factor, el entonces director del diario, Alejandro Fernández Pombo, lo dejó muy claro en una entrevista registrada en el año 2004:

"Se dejó ver que nos había sorprendido el nombramiento y mantuvimos una reserva inicial, pero le apoyamos tras conocer su Gobierno, en el que los ‘Tácitos' estaban muy representados. Y muchos de ellos eran incluso consejeros del Ya. Sabíamos que eran hombres que pensaban en nuestra línea. Salió un equipo que no podía ser más en la línea de Ya. Nos pareció muy oportuno" (Zugasti, 2007b: 69).

Es a partir de otoño de 1976, y con los preparatorios para el referéndum sobre las reformas políticas a la vista, cuando el diario intensifica su respaldo a Suárez. Ya le otorga un papel reformista e impulsor con un nuevo aire diferente al del antiguo régimen y con ganas de llevar a España a un horizonte europeo y occidental. Concede un importante protagonismo a las reformas políticas institucionales y considera que un Referéndum sobre las mismas es la única vía para una transición pacífica, auténtica, legal y democrática ${ }^{27}$. Se presenta claramente a favor de la convocatoria de elecciones generales y refuerza cualquier paso hacia la clarificación del paisaje político y electoral ${ }^{28}$. Los editoriales del diario revelan "una actitud reformista moderada, propia de la democracia cristiana frente al continuismo o la ruptura. Abundan las referencias

24 Ya. "Un gobierno nuevo". 09/07/1976

25 "Nuevo Presidente" 04/07/76; "Compromiso con el cambio" (06/07/76); "El gobierno que se espera” (06/07/76); "Intentarlo entre todos" (07/07/76); “Nuevo gobierno (08/07/76); “La Operación habrá de ser juzgada por su éxito” (08/07/76); “Un gobierno nuevo” (09/07/76); Programa de gobierno" (18/07/76) “La política como deber” (20/07/76); “Gobierno y estado fuertes” (20/07/76).

26 Ya. "El primer gobierno del Rey”. 06/07/1976.

27 Esto se ve reflejado en editoriales como "Para preparar el referéndum”. (02/02/1976).

28 Esta postura queda patente en piezas como “Urgencia” (11/09/1976), "El único camino es el democrático” (21/09/1976), "La reforma política en las Cortes” (21/10/1976) o “La Reforma, adelante” (19/11/1976). 
a “concordia”, "pacto” y “diálogo" (Arroyo Cabello: 221). El mismo día del Referéndum Ya publica un editorial que no podía hablar más claro: "Vote usted sí" (15/12/76) ${ }^{29}$.

Con el referéndum refrendado, Ya cambia de estrategia y presenta Suárez ahora no tanto como la antítesis del continuismo de Arias Navarro, sino como el baluarte de la democracia cristiana y representante de un "centro" político que puede evitar las viejas hostilidades entre derecha e izquierda. En el juego partidista preelectoral "Suárez", "centro"30 y "democracia cristiana” ${ }^{31}$ coinciden como palabras claves que marcan el discurso del diario en el camino hacia las primeras elecciones libres de junio de 1977. Una vez ya en plena precampaña Ya apuesta de forma muy clara por él, tal y como se ve en el editorial "Suárez, candidato":

"la gran mayoría sensata del país habrá cogido con alivio la noticia de que el presidente Suárez se presenta a las elecciones...el país necesita un centro, que sin el centro no vemos manera de evitar que volvamos a las andadas y que sin Suárez no había posibilidad de que ese centro sociológico...encuentre una vía lo bastante amplia para estar representado en las próximas Cortes como hace falta...si Suárez no se hubiese presentado, todo saldría peor"32.

En las semanas previas a las elecciones, y a pesar de las presiones de la Coalición Democrática de Fraga para que el periódico le apoyase (Arroyo Cabello: 225), los editorialistas del Ya se entregan por completo a la UCD y casi todos sus colaboradores más prolíficos se pronuncian abiertamente a favor de la formación de Suárez ${ }^{33}$. Estabilidad. Serenidad. Sensatez. Equilibrio. Responsabilidad. Moderación. Convivencia. Sentido común. Estos conceptos -presentes todos en el mantra diario del $\mathrm{Ya}$ - van vinculados constantemente a Suárez para demostrar que UCD es la única opción razonable.

Al abogar por la "educación política", Ya pide a sus lectores "madurez" para que no voten en función de personalismos ni por emociones. A solo cinco días de las elecciones, el diario se encarga de avisar en contra del "peligroso triunfalismo" y destaca que estas elecciones ponen fin a un proceso duro y difícil que ha sido posible gracias al Rey y a un gobierno que

29 Ya. "Vote usted sí". (15/12/76).

30 Esto se ve en titulares como “El centro como opción que obliga al dialogo” (07/01/77); "La unión del centro” (08/01/77); “El centro democrático" (21/01/77); “El centro democrático y los democristianos” (02/02/77); “Un centro y solo uno” (11 febrero), "La democracia cristiana, ¿ con el centro?” (17/02/77); “Sentido común y sentido político” (1 de marzo), ¿¿Dónde está el hombre del centro?” (29/03/77); "Pasos hacia la coalición del centro" (06/04/77); "Responsabilidad del centro" (19/04/77); "El centro y la estabilidad de la democracia” (20/04/77) "Democracia cristiana y centro democrático" (03/05/77); "Las candidaturas del centro democrático" (11/05/77); "No basta con un centro electoral, hace falta un centro político" (13/05/77); “El centro amenaza” (11/06/77).

31 "Las mil caras de la democracia cristiana" (28/08/76); "Sobre la identidad democristiana" (29/08/76); "La unidad en la democracia cristiana” (11/09/76); “Unidad de la democracia cristiana, ya” (29/11/76); “Democracia cristiana” 29/05/77.

32 Ya. "Suárez, candidato". 04/05/1977.

33 Attard, Emilio. "Las razones de nuestra coalición electoral” 26/05/77; Rodríguez, Federico. "Democracia cristiana” 28/05/77. Tusell, Javier. "Las candidaturas del centro democrático” (11-05-77). 
ha permitido el juego democrático. Ambas ideas aparecen reflejadas en el editorial titulado "Vote convivencia" publicado el 15 de junio, que concluye con una metáfora médica: "cuando el enfermo está en la mesa de operaciones, no es hora de ensayos ni de experimentos, sino de ponerse en manos de aquél de quien podemos estar seguros”.

No es de sorprender que, después de una apuesta tan clara, el diario se congratule con la victoria de su candidato. En un editorial una semana después de las elecciones, el diario saca pecho al afirmar que:

"Defendimos la participación del presidente del Gobierno, contra el parecer de muy importantes colegas de la prensa de las más opuestas significaciones políticas (...) y contra opiniones muy autorizadas que (...) disintieron de nosotros. Ni nos ha mandado ni nos manda Suárez (...) no era su persona lo que nos importaba, sino la necesidad de una fuerza política que equilibrase la del socialismo. No es que el Centro fuese Suárez (...) sino que sin Suárez no habría cristalizado políticamente: nos alegra no por nosotros, sino por el país, haber comprobado que no estábamos equivocados" ${ }^{34}$.

\subsection{Ya ante los desafíos democráticos: terrorismo, amnistía y el PCE}

Paralelamente al seguimiento de los protagonistas políticos en el año y medio que transcurre entre la muerte de Franco y las primeras elecciones democráticas, la agenda política del país pone a prueba el discurso aperturista del Ya. En ella figuran tres temas especialmente destacables por su calado político: el terrorismo, la amnistía y la legalización del Partido Comunista.

La violencia política acapara una atención cada vez mayor en los editoriales del rotativo. El periódico muestra su clara oposición a ETA ya que se niega a que los "asesinos de la paz cívica" ${ }^{35}$ puedan dictar la marcha del proceso democrático y reacciona indignado ante la oleada de asesinatos y secuestros, como se ve en editoriales como "ETA es delito en cualquier código penal" ${ }^{36}$, o en su respuesta a casos concretos como el del asesinato, en octubre de 1976, del presidente de la Diputación de Guipuzcoa, Juan María de Araluce:

"los criminales atentados del terrorismo son una trampa; que lo que pretende es paralizar la pacífica evolución política del país (...) las balas terroristas no van solo contra quienes las reciben, van contra cuantos también desde la oposición quieren sinceramente libertad y paz... [hay que promover] la rápida culminación de un pro-

34 “La lección de las elecciones”. 23/06/77. Una semana más tarde, y en una línea muy similar, José Luis Álvarez publica en la sección editorial un artículo titulado "Por que ganó el Centro", donde afirma que "la razón primera de este éxito está en haber conectado e interpretado (...) el deseo de la mayoría del pueblo. La oferta de moderación, de convivencia, de respeto a todos (...) una opción intermedia, sensata, lejos de los extremos en la respuesta adecuada para ese deseo (...) No cabe duda que la presencia de Adolfo Suárez en las listas ha sido muy importante por su prestigio como líder y como político capaz que ha sabido dirigir el cambio” (29/06/77).

35 Ya. "El terrorismo no debe condicionar la política". 13/02/1976.

36 Ya. "ETA: Es delito en cualquier código penal". 30/03/1976. 
ceso político cuya prolongación solo puede favorecer sucesos como el que hoy lloramos y acaso provocar decisiones extremas de una sociedad que no puede resignarse a este desangrarse, gota a gota" ${ }^{37}$.

Además de la condena de la violencia en sí, Ya reitera que el país no puede echar marcha atrás en su evolución política sobre todo después de los resultados del referéndum que refrendaba las reformas democráticas. Un editorial característico de esta preocupación se ve en su reacción al secuestro por GRAPO de Antonio María Oriol y Urquijo, presidente del Consejo de Estado. Según el diario, este acto

"pone de relieve la mínima eficacia de estos actos terroristas frente a la opinión pública (...) el pueblo español comprende sin dificultad que no hay Gobierno, por muy fuerte que se crea, capaz de prevenir un golpe de esta naturaleza (...) todo ello nos lleva a ponderar el magnífico comportamiento del pueblo español impresionado pero no condicionado en el ejercicio de sus derechos por la deleznable presión de los terroristas. Si en el referéndum han sido vencidos los extremos y ha triunfado la moderación, los terroristas no han sido ni siquiera tenidos en cuenta de cara al futuro" 38 .

Los asesinatos de los abogados laboralistas de Atocha en enero de 1977 representan una importante prueba de tolerancia y firmeza. El rotativo pide una "Respuesta apropiada y serena" ${ }^{39}$ y Tácito avisa a sus lectores que la violencia tiene un triple objetivo: boicotear el resultado del referéndum, la credibilidad del Gobierno y el arraigo de la Corona ${ }^{40}$. Estos miedos aparte, el diario asegura que los asesinos no vencerán en el editorial “Los españoles ganaremos”:

"nada de entreguismo a la subversión, nada de miedo ante el desafío criminal, nada de vacilación en la búsqueda del objetivo final democrático (...) el miedo sólo es combatible con la construcción acelerada de una nueva sociedad democrática, respecto a la cual los espectros terroristas no son más que diminutos márgenes de incalificables intereses (...) estamos seguros de que la sociedad española (...) sabrá conquistarla a pesar de las bombas, los secuestros y las metralletas de los asesinos" ${ }^{41}$.

La gestión sensata de la amnistía política es un tema que Ya considera fundamental para la consolidación del cambio democrático desde los primeros días de la Transición. Solo un mes después de la muerte de Franco, el diario hace pública su posición con un editorial en donde dice "nos parece muy bien, y muy oportuna, que se conceda la más amplia amnistía a los llamados delitos políticos esto es, de ideología; toda la generosidad respecto de ellos merece aplauso” ${ }^{2}$. Esto dicho, el

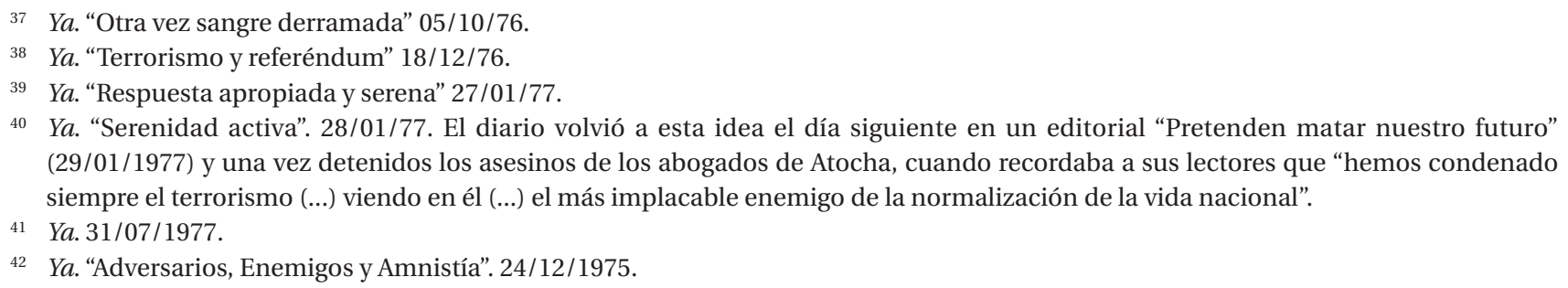


diario es muy crítico con el indulto inicial tras la jura del Rey, por haber liberado "miles de delincuentes comunes". En un editorial con tono de cierta indignación explica que

"Ya está a favor de la amnistía "por delitos estrictamente políticos", pero pedir otro tipo de amnistías que alcancen a los terroristas nos parece un planteamiento ofensivo para la España sana. Un país puede perdonar, pero esto es completamente distinto a perder la memoria y entregarse indefensos a quienes con sus palabras y su conducta han demostrado que no se arrepienten de nada y están permanentemente dispuestos a reincidir" 43 .

Frente a la inevitabilidad de las medidas de amnistía, el diario se embarca en una campaña didáctica para explicarlas en términos que respondan al perfil de sus lectores ${ }^{44}$. Lo hace apelando a "una amnistía espiritual”, que tiene "mucho más alcance y fuerza que la legal”45, e invocando el "perdón” que, según Emilio Attard, uno de sus editorialistas más destacados, "debe ser el auténtico significado con el que interpretamos la amnistía otorgada" ${ }^{4}$.

La legalización de la formación comunista planeó constantemente sobre el espacio editorial del Ya a lo largo de 1976 y durante la primavera de 1977. Desde sus páginas, el diario defendió la legalización del partido bajo el argumento que ésta era preferible a la clandestinidad, desde donde el partido podía atraer más adeptos:

"La derecha española adolece de un deslumbramiento anticomunista que le impide considerar que la legalización pudiera ser una táctica más hábil que forzar a la clandestinidad. A ese deslumbramiento atribuimos el que las Cortes hayan preferido la fórmula aparentemente más anticomunista, pero en el fondo menos eficaz”47.

La cobertura de la legalización del PCE comienza con una serie de editoriales de carácter didáctico en donde se explica su historia, política económica, relación con otros partidos comunistas europeos y ofrece un perfil de sus líderes ${ }^{48}$. El diario avisa al partido que "no pretendan darnos lecciones de libertad y de participación ciudadana en el poder (...), conviértanse primero a la democracia" ${ }^{49}$. Y el lema del PCE como partido profundamente antidemocrático se repite durante meses, junto con su falta de confianza en la figura de Santiago Carrillo:

"no creemos en su buena fe democrática (...) y esperamos siempre de él la trampa, pero creemos que los riesgos de mantenerle en la ilegalidad son mucho mayores (...) peor todavía es invitarle a que se camufle dentro del

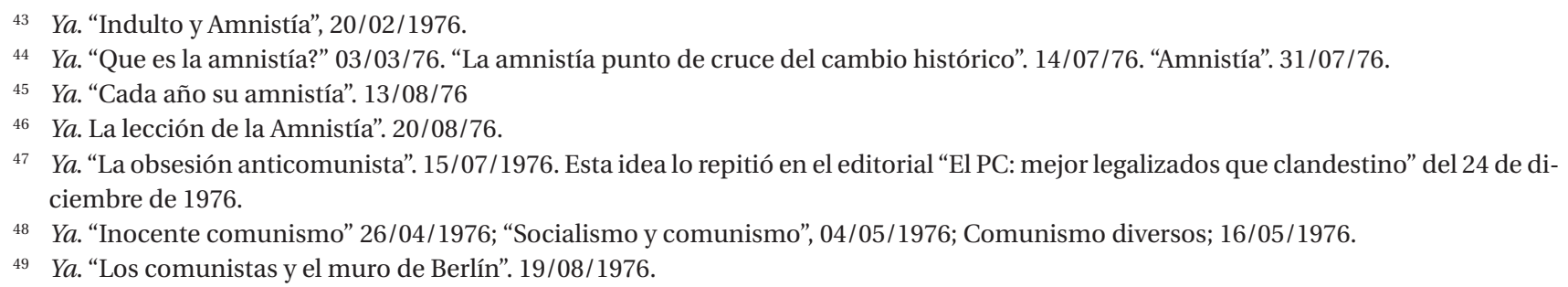


Partido Socialista de cuyos votos y de cuyos cuadros el comunismo se apoderaría (...). Esto hay que evitar que se repita"50.

A pesar de esta carga crítica en contra del partido, el diario prepara a sus lectores para la inminente legalización del PCE. Para ello, ofrece una batería de argumentos justificatorios que oscilan entre los beneficios de salir de la clandestinidad ${ }^{51}$, lo ventajoso que sería para todo el proceso de la Transición ${ }^{52}$ y la necesidad de combatirlo en la esfera democrática: "Este periódico es firme y tradicional baluarte contra el comunismo pero en el terreno donde hay que empezar a combatirlo es en el de la doctrina, en el de la justicia, en el de la libertad individual (...) sólo para eso se debe ser anticomunista pero aceptando el hecho que los comunistas existen (...) ¡sentido común, señores por favor!"53.

$Y a$ acaba aprobando la legalización del PCE como un acto de "prudencia política" ${ }^{4}$, una posición que queda resumida en los títulos de dos editoriales - "Se ha hecho lo que procedía” y "No al comunismo; sí a la legalización del PCE”- en los días posteriores a la medida ${ }^{55}$. Más adelante, el propio director del diario, Fernández Pombo, hablaba de la decisión de apoyar la legalización del PCE en los siguientes términos: "Precisamente porque queríamos que las cosas se hiciesen bien Ya defendió siempre que se autorizase el registro del Partido Comunista (...) algunos nos acusaron de rojos y traidores a nuestros principios por hacerlo. ¿Pero cómo podría hablarse de una democracia si se empezaba con las exclusiones?” (Cantavella y Serrano, 2010: 274).

Una vez asimilada su legalización, el diario adopta un tono más severo con el partido ya que solo quedan dos meses para las elecciones. Augusto Assia escribe un artículo titulado "No por haber sido reconocido el partido comunista ofrece más verosimilitud democrática ni más confianza" ${ }^{56}$, junto con unos cuantos más críticos con el partido. Como explicaba García Escudero, $\mathrm{Ya}$ "no cree en el comunismo, ni en la sinceridad democrática del partido (...) se trata, en definitiva de ser anticomunista con la cabeza; no visceralmente" (1984: 29). El diario reta al partido a "demostrar con hechos que es verdad lo que alegan para entrar en la legalidad. No basta solo con palabras” 57 , y recibe con hostilidad la llegada de la Pasionaria

50 Ya. "Carrillo y su partido". 24/12/1976.

51 "Sería suicida cerrar los ojos a la gravedad de la situación que se plantearía si se negase la legalización del PCE (...) nosotros lo hemos defendido (...) porque pensamos que los inconvenientes de su clandestinidad son muchos y en cambio las ventajas de su legalización son graves (...) el comunismo está ahí; no se le puede ignorar y lanzarlo legalmente a la ilegalidad será catastrófico.” Ya. "La legalización del partido comunista". 31/03/77.

52 "Hágase lo que procede sin perder días...un error no puede cancelar los éxitos de muchos meses ni podrá justificar que se privase al país que ha demostrado dotes políticos sobresalientes en la delicada operación de la transición”. Ya. “Decisiones”. 02/04/1977.

53 Ya. "El verdadero programa anticomunista" 25/04/1977.

54 Ya. "Anticomunismo". 14/04/1977.

55 Ya. "Se ha hecho lo que procedía”. 11/04/1977. “No al comunismo; sí a la legalización del PCE” 20/04/ 1977.

56 Ya. 13/04/1977.

57 Ya. "Se ha hecho lo que procedía". 11/04/1977. 
y la vuelta de Carrillo como se ve en un editorial dedicado exclusivamente a ellos a finales de mayo: "venir hoy de Moscú para cantar lo mismo que se cantaba antes de la guerra mundial es retroceder en el túnel del tiempo (...) hasta tienen los mismos trucos dialécticos..." ${ }^{58}$. Después de la llegada de la cúpula del partido desde el exilio, el PCE pierde protagonismo en la agenda editorial del diario.

\subsection{Ya y el primer gobierno democrático de Suárez}

Respaldado por la legitimación en las urnas, el primer gobierno democrático de Suárez cambia su foco de atención y se dirige hacia las evidentes tensiones en materia de la organización territorial del Estado y sobre todo hacia Cataluña y el País Vasco. La visita de Tarradellas a Madrid fija Cataluña en la agenda del diario y en el editorial titulado "El restablecimiento de la Generalitat" se adopta un tono de moderación al querer constatar que todos han cedido: "nadie está satisfecho al ciento por ciento. No hay vencedores ni vencidos y todos han tenido que ceder parcelas importantes de lo que fueron sus deseos...Este acuerdo contribuye a la armonía nacional y será un factor de distensión" ${ }^{9}$. En un editorial monográfico aplaude la prudencia de todas las partes implicadas y hace una comparación crítica con la proclamación de la República:

"Ya aplaude la manera sensata de abordar el problema catalán (...) Esta vez no ha habido ningún Macià adelantándose a proclamar la República catalana y produciendo un enfrentamiento y traumatizando la vida de la República. Ahora ha sido el Gobierno el que se ha adelantado a negociar. El buen sentido de los señores Suárez y Tarradellas ha hecho lo demás, respaldados por la moderación del pueblo catalán y por la actitud del todo el pueblo español que nada ha tenido que ver con las crispaciones de 1931 y 1932 "60.

La vuelta de Tarradellas a Barcelona es bien recibida por Ya aunque no sin advertencias al avisar que "la Generalidad no significa el fin de sus males ni la panacea que acabe con sus preocupaciones (...) En tan poco tiempo se ha avanzado tanto en la consecución de las libertades públicas que, en las regiones históricas, tiene que tener, forzosamente, un sentido de autocontrol en el ejercicio..." ${ }^{\prime 1}$. En sintonía con su apuesta habitual por la "sensatez", Ya felicita al pueblo catalán por haber confiado en el que considera una figura responsable a la vez que no deja de insistir que la Generalitat no deja de ser una concesión por parte del Estado:

"el pueblo catalán ha encontrado en él al hombre que necesitaba para llevarle hasta aquí...Gran fortuna ha sido que al "seny" catalán haya correspondido el "seny" del Rey y de su presidente del Gobierno....Lo que un Borbón quitó a los catalanes, otro Borbón se lo ha devuelto” ${ }^{2}$.

\footnotetext{
Ya. "La Pasionaria y Carrillo". 25/05/1977.

Ya. "El restablecimiento de la Generalitat" 10/09/1977.

Ya. "La Generalidad restablecida”. 30/09/1977.

Ya. “Tarradellas y la Generalidad”. 25/10/1977.

Ya. “Dialogo y pacto". 26/10/1976.
} 
Emplear un tono conciliador y apelar a la responsabilidad en un contexto comparativamente pacífico como el catalán resultó ser una tarea más fácil en comparación con el intento de lograr el mismo propósito en el País Vasco donde, en un contexto enmarcado por violencia y terrorismo, el peligro de vacilar por lo que se refiere al avance democrático estaba siempre presente. Por encima de todo, Ya intenta considerar a ETA como un obstáculo a la democracia y un retroceso en la consolidación del estado de derecho, pero el goteo constante de asesinatos de policías y políticos en la segunda mitad de 1977 y a lo largo del año 1978 acaba llevando el diario a una indignación palpable, como se ve ante el asesinato del comandante Joaquín Imaz en Pamplona a finales de noviembre de 1977:

"La ETA no lucha contra el franquismo que ya acabó en la Historia. Lucha contra todo lo que signifique libertad humana para imponer el dictado del gatillo (...) El pueblo navarro no es separatista ni cómplice de asesinos...Navarra va hablar y con ella, toda España....Un Estado democrático y popular debe aceptar su precio por consolidar la democracia. Ese precio empieza por acabar con la ETA ${ }^{63}$ ".

En el verano de 1978 se añade a la lista de víctimas de ETA el periodista José María Portell, hecho que lleva al diario a preguntar en un editorial “ $¿$ Hasta cuando?”:

"El que esta vez se haya escogido como víctima a un hombre de nuestra profesión...tiene una significación peculiar...el terrorismo no se dirige ya únicamente contra los encargados de mantener el orden público sino contra quienes representan los valores indeclinables del pensamiento. Sin una prensa libre, ¿qué régimen libre puede ser posible? (...) ¿Hasta cuándo van a seguir las vacilaciones y ambigüedades que lamentamos ante los fríos, brutales irracionales golpes del terrorismo?" 64 .

Cuando quedan prácticamente suspendidos los Sanfermines en julio, el Ya sube el tono y pide medidas de todas las instancias posibles: "La paz pública no es una cuestión de Gobierno sino de Estado. O el Estado la resuelve o cualquier día nos quedamos con el Estado entre las manos. También ahí jugamos con fuego" ${ }^{65}$. Ante el asesinato del teniente coronel Juan Antonio Pérez Rodríguez y el general de brigada Juan Manuel Sánchez-Ramos Izquierdo en Madrid, el diario exige el final de las palabras y el paso a la ofensiva directa al declarar que "no pedimos milagros: nadie cree que el terrorismo se puede desarmar en un solo día. Pero mientras no se actúe contra él sin reservas...será inevitable que haya quienes sólo sepan comentar: palabras, palabras, palabras...”66. Frente a “ese cáncer que esta devorando al País Vasco y puede acabar devorando a España entera” ${ }^{67}$ el fenómeno terrorista lleva al diario al límite de una tolerancia ampliamente mostrada en otros esce-

\footnotetext{
Ya. "El precio empieza por acabar con la ETA". 29/11/1977.

Ya. “¿Hasta cuándo?” 29/06/1978.

Ya. “Jugar con fuego". 11/07/1978.

Ya. "No solo palabras". 22/07/1978.

7 Ya. “Terrorismo y Constitución”. 31/10/1978.
} 
narios políticos propios de la Transición y amenaza con comprometer su discurso habitual de sensatez, convivencia y orden cívico.

\subsubsection{La Constitución}

A igual que con el referéndum sobre la reforma política de diciembre de 1976, Ya adopta el mismo planteamiento de "Si usted vota no" (del 5 de diciembre) o "Si usted vota sí” (6 de diciembre) a la hora de posicionarse sobre la nueva Constitución. En cuanto al primer editorial, el diario considera la Carta Magna como una “!posibilidad de convivencia que podría no volverse a repetir y para la que no descubrimos otra alternativa que la catástrofe!”68 - y se niega a regalar a los extremismos -tanto de izquierda como derecha- la posibilidad de paralizar todo el trabajo en el recorrido del avance democrático. Para reforzar su posición, al lado de este editorial publica un artículo titulado “La Hora del Sí”69.

El mismo día de la votación, el diario argumenta que los votantes del "sí” ratificarán el acuerdo entre las diferentes fuerzas políticas y se habrá permitido un "marco común para resolver pacíficamente las diferencias ideológicas sin tener que recurrir al golpe de Estado ni a la revolución [y así] poner fin a la triste cadena de guerras como las que, durante dos siglos, ha sido nuestra historia"70. Una vez celebrado el referéndum, Ya felicita a los españoles por haber garantizado que "ninguna opción política podrá salirse del marco ni hacia la derecha ni hacia la izquierda”, por haber respetado los “derechos de las minorías” y, en tercer lugar, por haber diseñado una arquitectura jurídica según la cual "ningún cambio [político] será irreversible [y por haber] logrado un texto que pudiese ser suscrito por todos"71.

\subsubsection{Las elecciones legislativas y municipales de 1979}

A la hora de congratularse por la victoria de UCD en las legislativas de marzo de 1979, Ya interpreta los resultados como un respaldo al reformismo moderado que ha predicado desde la muerte de Franco, en el cual "no ha habido revolución ni ruptura ni reacción dictatorial, se ha mantenido un sistema civilizado de convivencia. No es poco"72. El diario habla de la "madurez política” del pueblo español, de la gran derrota de los "extremismos” y la victoria del "partido de la moderación”73. Lo que Felipe González llama “el voto del miedo”, Ya llama el "voto de la sensatez"74. El diario concede que España necesita un partido fuerte de centro-izquierda pero avisa al PSOE que la derrota es una consecuencia del silencio sobre el “carácter marxista” de su programa.

\footnotetext{
Ya. "La pastoral del primado". 30/11/78

Ya. "La Hora del Sí”. Ya. 05/12/78.

Ya. "Si usted vota sí". 06/12/78.

Ya. "La Constitución de todos los españoles". 07/12/78.

Ya. "Después de las elecciones". 02/03/1979.

Ya. "Una política para cuatro años." 03/03/1979.

Ya. "La encrucijada del socialismo". 05/03/1979.
} 
Los resultados de las primeras elecciones locales de la democracia resultan ser el primer trago amargo por el partido apoyado por $\mathrm{Ya}$, y es a partir de ese momento en el proceso transicional que podemos observar ciertos cambios en el tono editorialista del diario. Su preocupación es doble: por un lado está la derrota de UCD en sí -que el diario achaca al abstencionismo alto- y, por otro, observa con preocupación cómo los partidos izquierdistas -principalmente PSOE y PCEmaniobran para lograr mayorías en gran parte de las administraciones locales, ya que ve en esta operación "una peligrosa vuelta a la polarización del país. No nos parece esta la más grave sino que el partido dominante dentro de la izquierda llegue a ser el partido comunista (...) que con la táctica revolucionaria no había cosechado más que fracasos... ${ }^{75}$.

\subsection{Las autonómicas de 1980}

Después de las elecciones locales llegan los comicios autonómicos de marzo de 1980. La continuada pérdida de peso del "centro" político que representa UCD irrita al diario. En el caso del País Vasco, el rotativo arranca su cobertura preguntando "si la campaña trata de autonomía o de independencia" y desacredita sus partidos nacionalistas cuyas actuaciones

"obligan a pensar con alarma en las decisiones que pueden tomar el Parlamento y el Gobierno futuros (...) ya que se trata de los portavoces legalizados de las dos ramas del terrorismo, Euskadiko Ezkerra y HB, pero también de ese PNV que una vez más ha puesto de relieve con su mezcla de ambigüedad, vaguedades, medias tintas y miedo, que no es un interlocutor con el que, sin duda, se soñó en la Moncloa para llevar adelante el proceso autonómico vasco"76.

Frente a lo que considera como la incapacidad del PNV de defenderse ante el "tirón demagógico" de la izquierda abertzale, $Y a$ abandona su moderación tan característica en un último intento de apelar al "voto sensato" de los vascos, ya que "en ese rincón de la patria parece haberse apoderado la locura...Cuando está en juego el ser o no ser del País Vasco y se puede producir una quiebra profunda en la unidad española"77.

Para el diario, la victoria de Garaicochea es el resultado de una “irresponsabilidad” y un

"miedo que desde hace mucho tiempo circula en el País Vasco a todos los que se atreven a sentirse, además de vascos, españoles....", pero también de "errores concretos de UCD que ha sido la más perjudicada"78.

En Cataluña, en cambio, sí existe una fuerza política que actúa como contrapeso a los nacionalistas de CiU pero no es una alternativa que entusiasma el diario: "El gran peligro lo vemos en un gobierno de socialistas y comunistas cuyas conse-

75 Ya. "Historia para socialistas". 11/04/1979. En su último editorial sobre esta cuestión, Ya se queja de que "el pacto entre PSOE y PCE no figuraba en su día en la campaña electoral, pero agua pasado no mueve molino" ("Nuevos ayuntamientos" 19/04/1979).

76 Ya. "Responsabilidad para la autonomía vasca". 04/03/1980.

77 Ya. "Hace falta que voten los vascos sensatos". 06/10/1980.

$78 Y a$. "La lección de las elecciones vascas". 10/10/1980. 
cuencias serían catastróficas para Cataluña y para España [los electores] deben hacerlo imposible dando sus votos a los candidaturas no marxistas (...) ¿quién se puede fiar? Tomen los electores buena nota"79. El diario considera que el papel de Cataluña en todo el proceso de la transición política española ha sido ejemplar y, como diario centrista que es, señala el dilema en que se encuentran sus votantes: o "nacionalismo exacerbado" o el "marxismo":

"A Cataluña le corresponde una indiscutible capitanía moral en la defensa de las autonomías, cuya bandera ha alzado ella sola durante mucho tiempo...ha sido durante la transición un ejemplo de ponderación en la defensa de su autonomía y un factor decisivo de estabilización en la política general española. Seria fatal que esa línea se quebrase hoy y se puede quebrar por los dos extremos: por la consiguiente hipertrofia de un nacionalismo exacerbado como el que hace hablar de un Estado catalán o por el triunfo de una concepción marxista de la vida..." ${ }^{80}$.

Para Ya, la victoria del nacionalismo catalán no solo demuestra "dónde los votantes han depositado su capacidad de ilusión política” ${ }^{81}$ sino también el desgaste de los partidos de alcance estatal y en especial, UCD.

\subsection{Crisis de UCD: la apuesta moderada llega a su fin}

La crisis del partido centrista es el principal tema editorial del diario a principios de 1981. Las críticas hacia la formación de Suárez coinciden con las victorias electorales del PNV y CiU y las propuestas federalistas inquietan a Ya, llevándolo a decir que "hay partidos que proponen un Estado federal agitando el fantasma del centralismo cuando si de algo padece hoy al país no es del Estado centralista sino de que en el centro falta precisamente un Estado” ${ }^{82}$. El Congreso del partido -previsto para finales de enero- sirve a Ya para pedir la renovación del partido, que pasa por una subordinación a la base $^{83}$, mantenimiento de la unidad, listas abiertas y un programa claro que responda al perfil conservador de sus votantes:

“Con razón se ha dicho que si UCD no existiese habría que inventarla, pero una UCD que responda a aquéllo que ha representado y debe seguir representando...El problema no es que UCD no tenga programa sino que muchos de quienes la votaron se preguntan donde está el programa que votaron; lo buscan y no lo encuentran....." 84 .

79 Ya. "Elecciones en Cataluña”. 16/10/1980.

80 Ya. "Lo que se vota hoy en Cataluña". 20/10/1980.

81 Ya. "La victoria del nacionalismo catalán". 22/10/1980.

82 Ya. "Al que no quiere caldo". 03/01/1981.

83 “Tenemos el convencimiento de que todos los males de UCD son consecuencia del olvido en que ha tenido a su base..." Ya. "No tendencias, sino electores". 04/02/1981.

84 Ya. "Los pies sobre la tierra". 22/01/1981. 
A finales del mes de enero llega la dimisión de Suárez. El diario reacciona fríamente a la noticia y pide no "dramatizar un acto que, en un régimen democrático, forma parte del juego político". Mientras reconoce "el gran servicio que prestó a la transición”, el diario considera que "las mismas cualidades que le habían permitido tales resultados se volvían ahora contra él...Su inadecuación para la política que hacer en esta etapa era una convicción popular y todo hace sospechar que el hecho de que su propio partido llegase a compartir ese convencimiento ha sido el determinante de la decisión...". Lo que más parece preocupar al diario es el momento en se ha producido y, sobre todo, la posible búsqueda de apoyo de otros grupos que "podría llevar a la formación de un gobierno socialista o que entrasen los socialistas con aquellos hombres de UCD mas afines a ellos, lo que...representaría un fraude... a la voluntad popular manifestada en las elecciones ${ }^{85}$.

El diario tiene pánico a la convocatoria de nuevas elecciones. Opina que "el pueblo español no está para esas aventuras" y pide, ya que "lo que ellos no hagan lo harán otros en contra de ellos con riesgos de magnitud imprevisible para la nación” ${ }^{86}$. Según el diario, el Congreso no ayudó a revivir el partido. En un editorial titulado “Un Congreso para nada”, Ya se queja de cómo "la indefinición programática y el consiguiente entreguismo ideológico han hecho estragos entre la clientela electoral de UCD”87. El sucesor de Suárez tampoco entusiasma el diario. El diario apoya tímidamente a Calvo Sotelo, pero después de su investidura echa en falta "el discurso y la garra del político de raza, la capacidad de entusiasmar e ilusionar y arrastrar a un pueblo" ${ }^{88}$.

\section{8. $23-F$}

Según García Escudero, "detrás del golpe militar...había la serie de fallos de gobierno que el periódico venia denunciando infructuosamente desde hace años; el golpe militar era una consecuencia: el remedio equivocado a unas causas reales." (39). Uno de estos 'fallos' era el "deterioro general de los organismos y personas que presenciamos" con dos excepciones, el Rey y el Ejército:

“La Corona y el Ejército son las instituciones en que convergen las esperanzas del país...Nos apresuramos a aclarar que no creemos en golpismos ni cosas por el estilo...frente a la provocación de ciertos sectores de opinión irresponsables (...) El país ahora no está dividido...pero si no hay el peligro de la división, existe el de la progresiva disolución si no se atiende a los grandes problemas del paro, del orden público y de la unidad nacional. No hay más fórmula que formar una piña apretada...lo que hizo posible el denominado milagro de la Transición" ${ }^{89}$.

\footnotetext{
Ya. "Ante la crisis". 30/01/1981.

Ya. "No cerrar la crisis en falso". 31/01/1981.

Ya. "Un congreso para nada”. 10/02/1981.

Ya. "Un discurso serio". 19/02/1981.

Ya. 07/01/1981.
} 
Aunque el diario reitera que no cree que el golpismo sea la solución a los males del país, los actos terroristas etarras -y en concreto el asesinato del ingeniero jefe José María Ryan- le lleva, tal y como titula su editorial, al "límite de la paciencia nacional":

“Estamos hartos: España está cansada de tanto asesino que se autoproclama patriota y libertador (...) Hemos llegado al convencimiento de que la única terapia aplicable es la extirpación de ese cáncer que siega vidas y esperanzas. Tiene que existir un método, una forma de hacerlo. Por muy doloroso que resulte...Convencidos de que nos va en ello la supervivencia...Ha llegado el momento de la poda sin cuartel. La alternativa es tan simple como ésta: o ellos o España"90.

El 23-F provoca preocupación, tristeza, bochorno y vergüenza. En su editorial del día siguiente, el diario declara que "como españoles nos avergonzamos por nuestro país y por nosotros mismos....todos estamos manchados por el estallido de irracionalidad...una pesadilla que creíamos olvidada”, pero cierra filas en torno a "la Constitución como fórmula y al Rey como suprema garantía"91. Incluso en estas circunstancias el diario busca un terreno discursivo moderado cuando reclama "justicia pero nunca revanchismo” a la institución militar ${ }^{92}$, y se consuela con el comportamiento no sólo del Rey sino del pueblo:

"El ciudadano no entendió el lenguaje de la violencia (...) No hubo trauma. No hubo desaliento. No hubo reacciones airadas, hubo la fe en sí mismos que se contagia (...) El pueblo ha enseñado de nuevo a los políticos cuál es el comportamiento procedente...El pueblo ya se ha manifestado la noche del 23 con una prueba de madurez cívica" ${ }^{93}$.

\subsection{Acatamiento: la victoria del PSOE}

A pesar de sus demostradas reticencias sobre la llegada a la Moncloa de la izquierda, el diario encaja la victoria del PSOE con pocas críticas hacia la cúpula del partido. Tal y como anotó García Escudero, "las esperanzas del periódico en un socialismo moderno se concentran en Felipe González, quien resulta mejor tratado por Ya que lo fuera Adolfo Suárez en sus mejores momentos” (43). Este apoyo implícito a González venía de un año antes de las elecciones cuando el diario expone que "si en España llegamos a tener un socialismo moderno y responsable, ese socialismo debe pasar por Felipe González"94. La actitud del Ya queda resumida en su editorial titulado "Acatamiento y esperanza” el día después de las

90 Ya. "El límite de la paciencia nacional". 08/02/1981.

91 Ya. "Nos abochorna”. 24/02/1981.

92 Ya. "Justicia no revancha”. 28/02/1981. Para el diario no hay "nada peor que caer en la tentación del revanchismo o de someter a la institución militar a la injusta humillación de una purga aplicando criterios políticos que podría ser una torpeza que traería consecuencias imprevisibles. Justicia, pues, pero nunca revanchismo".

93 Ya. "El pueblo ya se ha manifestado". 26/02/1981.

94 Ya. "El secretario y su partido". 23/10/1981. 
elecciones ${ }^{95}$, y en un cierto deseo que "más que la victoria de un partido, habrá servido para consolidar la convivencia nacional" (García Escudero: 43).

\section{Conclusiones}

A través de un análisis de su trayectoria a lo largo de la transición democrática, hemos podido observar cómo el diario Ya intenta trazar una línea editorialista a favor del proceso democratizador y se convierte desde el sector conservador en uno de los patrocinadores del aperturismo político. En referencia a determinadas cuestiones del Estado -su rápida desaprobación de la gestión de Arias Navarro, su posicionamiento pro-amnistía y su aval a la Constitución- se puede observar cómo el diario abandona una posición neutral para dejar claro su apoyo al desarrollo político del país. En cambio, sobre otros aspectos el diario se muestra más pragmático -no al comunisimo, sí a la legalización del PCE- y, en ocasiones, más escéptico como se ve respecto a sus dudas iniciales -eso sí, compartidas entre toda la prensa- sobre Suárez y su tándem con el Rey.

Es una trayectoria no exenta de momentos difíciles -la violencia terrorista pone a prueba el tono reservado del diario junto con el evidente declive de UCD como baza electoral- pero cuando se trata de analizar su comportamiento político en los momentos clave de la Transición, el diario conservador se acopla al consenso generalizado que la reforma política es central a la construcción democrática del Estado, que la prensa es una parte implicada en esta labor y que su contribución será siempre acorde con los rasgos característicos que Ya se atribuyó a lo largo de los años de la Transición: la sensatez, el sentido común y la moderación.

\section{Referencias bibliográficas}

Alférez, A. (1986): Cuarto poder en España. La prensa desde la ley Fraga de 1966. Barcelona: Plaza y Janes.

Arroyo Cabello, M. (2010a): “La editorial católica en el consenso periodístico”, en Cantavella, J. \& Serrano, J. F. Los periódicos de la Editorial Católica. Madrid: Edibesa. pp. 213-231.

Barrera, C. (1995a): Periodismo y franquismo. De la censura a la apertura. Barcelona: Ediciones Internacionales Universitarias.

- (1995b) Sin mordaza. Veinte años de prensa en democracia. Madrid: Temas de hoy.

Bardavio, J. (2000): Todo Franco. Madrid: Plaza \& Janes.

Berelson, B. (1952): Content Analysis in Communication Research. Glencoe: Free Press.

95 Ya. "Acatamiento y esperanza". 30/10/1982. 
Cantavella, J. (2010): “Aquilino Morcillo, director del diario Ya (1952-1974”) en Cantavella, J. y Serrano, J. F. (2010a): Presencia e influencia de la Editorial Católica. Madrid: Edibesa.

Cantavella, J. y Serrano, J. F.: (2010b): Los periódicos de la editorial católica. Madrid: Edibesa.

Castro Torres, C. (2010): La prensa en la transición española 1966-1978, Madrid: Alianza Editorial.

Crespo de Lara, P. (2008): Informaciones. La década del cambio. Santander: Editorial Tantín.

Fernández, Pombo. A. (2010): “Historial parcial y ascendente del Ya”, en Cantavella, J. y Serrano, J. F.: Presencia e influencia de la Editorial Católica. Madrid: Edibesa, pp. 259-276.

García Escudero, J. M. (1984): Ya. Medio Siglo de Historia 1935-1985. Madrid: Biblioteca de Autores Cristianos.

Krippendorff, K. (2004): Content analysis. An introduction to its methodology. Sage: Thousand Oaks, California.

Martin Aguado, J.A. y Vilamor, J. R. (2012): Historia del Ya. Sinfonía con final trágico. Madrid: CEU Ediciones.

Montabes Pereira, J. (1989): La prensa del Estado durante la transición política española. Madrid: CIS.

Nogué, A. y Barrera, C. (2006): La Vanguardia. Del franquismo a la democracia. Madrid; Fragua.

Olmos, V. (2003): Historia de ABC. Madrid: Grandes Temas.

Powell, C. (1990): “The Tácito Group and the Transition to Democracy” en Lannon, F. \& Preston, P. Elites and Power in Twentieth Century Spain. Oxford: Clarendon Press, pp. 249-268.

Quirosa-Cheyrouze y Muñoz, R. (ed.) (2009): Prensa y democracia. Los medios de comunicación en la Transición. Madrid: Biblioteca Nueva, p. 63-76.

Rodríguez Jiménez, J. L. (2012): “La prensa de extrema derecha en la transición del franquismo a la democracia (19731982)", El Argonauta español, Disponible en: http://argonauta.revues.org/1421 [Consultado el: 15/11/2016] DOI : 10.4000 /argonauta.1421

Seoane, M. C. y Sueiro, S. (2004): Una historia de El País y el grupo Prisa, Barcelona: Plaza y Janés. Tacito. Artículos publicados. (1975): Madrid: Ibérico Europea de Ediciones.

Zabildea Bengoa, B. (1996): Prensa del Movimiento en España, 1936-1983, Bilbao: Universidad del País Vasco.

Zugasti, R. (2007a): La forja de una complicidad. Monarquía y prensa en la Transición española (1975-1978), Madrid: Fragua.

- (2007b): “La prensa española ante la designación de Adolfo Suarez como presidente del Gobierno en julio de 1976”, en Doxa Comunicación, n. 5. pp. 59-77. 